PALAVRAS. Revista de Epistemología, Metodología y Ética del Psicoanálisis ISSN: 2468-9831

www.revistas.unlp.edu.ar/palavras

palavras@outlook.com.ar

Argentina

\title{
RESEÑA DEL LIBRO “PSYCHOANALYSIS, A THEORY IN CRISIS". AUTOR: EDELSON, M. EDITADO POR: UNIVERSITY OF CHICAGO PRESS. 1988-392 PÁGS.
}

DOI $10.24215 / 24689831 \mathrm{e} 032$

Julia Zurita

\section{Cómo citar este artículo:}

Zurita, J. (2019). Reseña de: Edelson, M. (1988). "Psychoanalysis, a theory in crisis" Palavras. Revista de Epistemología, Metodología y Ética del Psicoanálisis, 5, 108-116 Recuperado de www.revistas.unlp.edu.ar/palavras 


\section{RESEÑA DEL LIBRO “PSYCHOANALYSIS, A THEORY IN CRISIS". AUTOR: EDELSON, M. EDITADO POR: UNIVERSITY OF CHICAGO PRESS. 1988-392 PÁGS.}

\section{Julia Zurita*}

Presentamos la reseña de la obra "Psychoanalysis, a theory in crisis", del psiquiatra estadunidense Marshall Edelson, publicada en el año 1988. La relevancia de reseñar dicha obra radica en no haberse traducido a nuestro idioma y en el escaso tratamiento en el ámbito local. Asimismo, el texto aborda temáticas actuales y revive las polémicas suscitadas por la utilización de los estudios de caso/s en Psicoanálisis.

Edelson nos hace saber que su impulso a escribir y analizar los temas desarrollados en esta obra se basa en su preocupación por el estado del psicoanálisis: desacreditado, desprestigiado como disciplina científica, con pocos avances en la comprensión y comprobación en su dominio de interés. Esta situación es resultado de no encontrarse debidamente aclarados los fundamentos conceptuales y modos de indagación, lo que lo separa de otras disciplinas o lo diferencia de otras ramas de la psicología, etc. No hay consenso en la comunidad psicoanalítica sobre estos tópicos, lo cual conduce a grandes inconvenientes para aquellos que pretenden enseñar el psicoanálisis, para quienes desean aplicarlo para resolver diversos problemas de orden práctico o teóricos. Como hace notar el autor, cualquier evaluación del estado actual del psicoanálisis se regirá de acuerdo a las suposiciones que cada quien tenga respecto a dos puntos; por un lado, el contenido de la base central de la teoría psicoanalítica y, por otro, las concepciones respecto a la ciencia, método y explicación científica. Por esta razón, el autor dividirá el libro en dos grandes partes. La primera se titula 'La teoría central del Psicoanálisis' y consta de diez capítulos. La segunda parte de la obra es titulada como 'El método de

*Facultad de Psicología, Universidad Nacional de La Plata.Mail: juliazurita1986@gmail.com 
estudio de caso en psicoanálisis' y se encuentra constituido por cinco capítulos.

"Psychoanalysis, a theory in crisis" constituye una obra densa, en donde el autor abordará distintas temáticas y recopilará material ya publicado con anterioridad, pero siempre con el objetivo de argumentar a favor de su tesis. Por ello, nos proponemos mencionar los puntos más sobresalientes, especialmente aquellos que son parte fundamental de sus puntos de vista y que conducen a su propuesta principal; esto es, establecer el dominio distintivo del psicoanálisis así como su defensa de la utilización de estudios casos, siempre y cuando no se aparten de los cánones del razonamiento y método científico.

En la primer parte de la obra Edelson se ocupará de esclarecer el ámbito de estudio propio del psicoanálisis, puesto que el no desentrañarlo condujo al estado actual de dicha disciplina, con los solapamientos de teorías, métodos, conceptos que se han ensayado. Así, llevará adelante una discusión con otros autores, específicamente con Heinz Hartman, que plantean que el psicoanálisis es una psicología general. Será en el transcurso de los capítulos subsiguientes- capitulo III y VI- donde el autor examinará con más detalle estas ideas. Sentará su posición. El psicoanálisis es una psicología intencional. Se ocupa de ciertas entidades, estados mentales, que poseen la propiedad de ser intencionales, es decir, estados mentales que incluyen una actividad psicológica dirigida a, o una representación mental sobre algún estado de cosas o algún objeto. Ahora bien, como psicología intencional, el psicoanálisis es una ciencia de la imaginación, en la medida en que su teoría de la realidad psíquica posee un rol explicativo central, y una ciencia del funcionamiento simbólico, por cuanto estudia los modos de simbolización que construyen representaciones mentales que son componentes de los estados de la imaginación. No obstante, las preguntas de investigación de un programa psicoanalítico no se referirán a todo el dominio de una psicología de la mente. No se preguntara como el sujeto es capaz "creer" o de "desear", sino por qué cree lo que cree; esto es, el psicoanálisis no explicará las 
capacidades, en todo caso las presupone, pero no forman parte de su dominio de interés. Será en función del contenido de los estados mentales en que el psicoanálisis basara sus explicaciones sobre las relaciones causales entre estados mentales, o entre estos y el ambiente o la acción. Asimismo, su foco se halla dirigido hacia las brechas causales en la vida de un sujeto, es decir, en aquellos fenómenos que resultan incomprensibles en tanto no se ajustan a los deseos y/o creencias concientes de un sujeto. Estas discontinuidades en las relaciones causales se deben a aquello que sí es distintivo del psicoanálisis, esto es, los estados mentales inconcientes y los conflictos y dilemas que suponen.

Por otra parte, en su afán de delimitar el ámbito específico del psicoanálisis, el autor analizará a lo largo de su exposición las relaciones de este con otros cuerpos de conocimientos. De esta manera, establecerá el lugar fronterizo que ocupa el psicoanálisis en el abanico de disciplinas, tanto humanas como naturales. En el capítulo 5 el autor se pregunta por la casi nula discusión con el psicoanálisis- e incluso la no consideración de sus hipótesis- en los estudios llevados a cabo por otras disciplinas, tomando como ejemplo el caso de la ansiedad. La tesis del autor es que las diferencias en los resultados no tiene que ver con el hecho de presentar hipótesis científicamente más creíbles sino con diferencias en los dominios elegidos por cada disciplina, es decir, diferencias en cuanto a qué dimensiones de la ansiedad pertenecen al ámbito de estudio del psicoanálisis y cuáles no. El autor hace notar que ninguna disciplina tiene por objetivo la explicación de todo. Por el contrario, circunscribe su dominio de intereses y si tiene éxito en la explicación del mismo podrá extender su poder explicativo a otros ámbitos.

En el capítulo siete, titulado Psicoanálisis y Neurociencias, el autor sostendrá que el psicoanálisis es una ciencia especial y autónoma, imposible de ser reducida por las neurociencias. Como ya puntualizamos, las entidades y preguntas acerca de dichas entidades que el psicoanálisis elige como propias a estudiar no son las mismas que abordan otras disciplinas, inclusive las neurociencias. Asimismo, Edelson plantea que los 
conceptos del psicoanálisis que forman parte de sus generalizaciones explicativas no son coextensivos con las leyes y conceptos de las generalizaciones explicativas de las neurociencias. En suma, lo que distingue al psicoanálisis es no solo su dominio de interés sino también su estrategia explicativa, con lo cual, si pasamos de los contenidos mentales a los estados neurofisiológicos perderemos el poder explicativo del psicoanálisis.

Por otro lado, en el capítulo siguiente, Edelson se dedica a la aplicación del conocimiento psicoanalitico a problemáticas provenientes de otras disciplinas; esto es, al psicoanálisis aplicado. Considera que cualquier intento de aplicación del psicoanálisis dependerá de la utilización o no del núcleo básico de la teoría, en particular, la importancia causal de las fantasias y de los conflictos inconcientes así como las dos formas de funcionamiento de la mente (i.e proceso primario y proceso secundario). La importancia del psicoanálisis aplicado no es menor. Constituye una garantía para la credibilidad de las inferencias causales al aportar evidencia sobre la existencia de aquello postulado por el psicoanálisis y permite descartar la incidencia de factores como la sugestión en la obtención de evidencia.

Una vez establecido el dominio distintivo del psicoanálisis, Edelson inaugura la segunda parte del libro. Se detendrá especialmente en algunas justificaciones del estudio de caso en psicoanálisis que parten de una concepción hermenéutica y cuyos efectos resultan perniciosos, puesto que conducen a un abandono de los cánones científicos por parte de los psicoanalistas. No obstante, el autor sostendrá una defensa de los estudios de caso pero a partir de justificaciones que no niegan el carácter científico del psicoanálisis. Ahora bien, las razones esgrimidas por gran parte de la comunidad analitica - la apelación a la subjetividad, el significado, la complejidad y unicidad de los fenómenos estudiados-, dice el autor, no imposibilita un tratamiento científico del corpus teórico y de la evidencia proporcionado en un estudio de caso. Los cánones científicos 
son para Edelson independientes de cualquier ámbito de estudio ${ }^{1}$.De acuerdo a su opinión, los defensores de los estudios de caso, se unen con sus detractores al relegar estos estudios al contexto de descubrimiento. El valor científico de dichos estudios reside en proporcionar argumentos respecto a la relación entre hipótesis y evidencia, ya sea brindando apoyo a las generalización empíricas- estas describen una regularidad de hechos, pero no se explican por sí mismas, teniendo que descifrarse su nexo causal- como a las explicaciones causales. Aun así, existen determinados argumentos que deben evitarse en un estudio de caso. Por un lado aquellos que suponen que la acumulación de datos favorables a una hipótesis le otorga mayor credibilidad científica. Por otro lado, la postulación de que dos fenómenos que co-ocurren durante nuestro estudio se constituyen en causas y efectos. Por el contrario, en un estudio de caso deberá poder argumentarse por qué los datos obtenidos proporcionan mayor evidencia a nuestra hipótesis que a alguna otra comparable o rival; se debe especificar qué datos podrían hacer que la hipótesis sea rechazada; $y$, se debe justificar que no han intervenido factores extraños a la hipótesis en cuestión en la obtención de datos favorables -como lo ha hecho Freud al intentar demostrar que la sugestión no es la causa de sus resultados-. Los últimos dos argumentos sobre la relación entre hipótesis y datos obtenidos en un estudio de casos son fundamentales a la hora de establecer la credibilidad científica, puesto que para ello no es suficiente que las hipótesis posean poder explicativo. De esta manera, el investigador que utiliza este tipo de estudios deberá exponer la hipótesis propuesta a un riesgo de rechazo. Ejemplos de este tipo de argumentos son ofrecidos por Edelson, y se cuentan entre ellos el argumento del rival derrocado, el argumento de la predicción de riesgo, en el que se puede utilizar cualquiera de los siguientes: (1) el argumento de caso menos probable; (2)

${ }^{1}$ Como se verá más adelante, el autor hace corresponder en un primer momento a los cánones del razonamiento científico con el inductivismo eliminativo, cambiando luego su posición. Se ha mencionado anteriormente que el libro está compuesto por material previamente publicado por el autor así como por material inédito que da cuenta de cambios en su pensamiento. 
el argumento de causa rara; (3) el argumento de resultado improbable; (4) el argumento de convergencia; y (5) el argumento bootstrap.-

En el capítulo 12 y 14, el autor realiza un análisis de la crítica de Grünbaum al psicoanálisis. Edelson coincide que gran parte de los estudios de caso en psicoanálisis no se han ajustado a los cánones del razonamiento científico. No obstante, eso no implica que los datos obtenidos en la situación analitica no sean suficientes para otorgar valor probatorio y credibilidad científica a las hipótesis psicoanaliticas, como sostiene el propio Grünbaum. Al afirmar esta insuficiencia de los datos, el filósofo de la ciencia termina acotando la investigación en psicoanálisis a la investigación extra clínica, es decir a la investigación epidemiológica y experimental. Por su parte, Edelson no desalienta la realización de estos tipos de estudios, pero mantiene el interés en los estudios de caso y los datos en ellos producidos. Edelson señala que cualquier crítica a los fundamentos que apoyan las inferencias causales clínicas del psicoanálisis, deberá tener en cuenta el tipo de teoría de la que se trata el psicoanálisis, así como la concepción de causalidad. Respecto al primer punto, el psicoanálisis no es una teoría jerárquica, deducible de otra teoría o a partir de un pequeño conjunto de axiomas o leyes. Por el contrario, el psicoanálisis se compone de teorias concatenadas, pero esencialmente independientes ${ }^{2}$. Esta es una de las razones por la cual las explicaciones psicoanalíticas no pueden ajustarse al modelo de explicación estándar de cobertura legal. Según este modelo los fenómenos a explicar se encuentran subsumidos bajo alguna ley general de la cual se deducirian. Por otro lado, la concepción de causalidad sobre la que se basa Freud es generativista y no sucesionista. Esta última se encuentra en la base de la crítica de Grünbaum, especialmente su idea de la falacia de inversión causal en la cual habria incurrido el propio Freud.

\footnotetext{
2 A partir de su análisis del Hombre de los lobos, Edelson sostiene que Freud utiliza teorias interrelacionadas, a saber, la teoría psicoanalítica de los sueños, la teoría psicoanalítica del desarrollo psicosexual y la teoría psicoanalítica de la neurosis.
} 
Ahora bien, las dos concepciones de causalidad son válidas y tienen sus usos en la ciencia. No obstante presentan diferencias. En una concepción sucesionista, una causa- a la que se le denomina causa necesaria- se presenta regularmente antes de un evento o estado. Las causas pueden ser descriptas sin hacer referencia al o a los posibles efectos y viceversa. Por el contrario, en una visión generativa, causas y efectos no son independientes, entre ellos existe una relación, un mecanismo o proceso causal que es estimulado por la causa y que produce un efecto -será a través de estos procesos como la causa transmite su influencia-. Aquí el conocimiento es de estructura (en el caso del psicoanálisis podriamos decir de contenido), puesto que la capacidad de generar un efecto es parte de la naturaleza misma de las cosas. Contrariamente a la que acontece en una visión sucesionista, donde lo que se conoce es la correlación entre tipos de eventos o fenómenos. La teoría sucesionista, para los autores como Edelson que siguen a Harré en su concepción de causalidad generativista, no explica nada, solo establece regularidades.

Para ahondar en la diferencia de concepciones Edelson recurre a la historia de la medicina en sus esfuerzos de establecer criterios para justificar su creencia en el papel del virus como agente causal de la manifestación de una enfermedad. Aquellos criterios debieron ser constantemente modificados y fue necesario el conocimiento de la naturaleza y el comportamiento del agente causal para caracterizarlos. Asimismo, tuvo que incorporarse el conocimiento del huésped y de las condiciones internas y externas que pudieran hacer que el virus se manifieste efectivamente.

Como se puede apreciar, aunque con diferencias, el caso descripto exhibe ciertas similitudes con el dominio propio del psicoanálisis. Un sueño, lapsus, síntoma, etc. no necesariamente se generará por el conflicto que cierta fantasía inconciente podría producir; puede que otras causas sean requeridas o que durante un cierto periodo de tiempo no produzcan efecto alguno. De igual manera, el ejemplo de las teorías virales le permite al autor reivindicar las inferencias causales psicoanaliticas, ya que tendrá 
que ser el propio psicoanálisis quien establezca los criterios para evaluarlas, siempre teniendo en cuenta la naturaleza de los fenómenos estudiados.

Por último, teniendo en cuenta que las explicaciones causales en psicoanálisis se basan en una concepción generativista, Edelson finaliza su obra apelando a lo que se conoce como Inferencia a la mejor explicación, y sostendrá que una buena explicación causal presenta muy pocas explicaciones rivales, si es que las tiene. La mejor explicación es aquella que refiere entidades teóricas no observables y que describe sus poderes causales y los mecanismos a partir de los cuales producen efectos. Asimismo, la mejor explicación es una explicación simple, en tanto se basa en el conocimiento ya establecido; esto es, hace uso de modelos. Edelson señala que el uso de modelos -tal como lo utilizó Darwin al construir su teoría de selección natural- es una de las maneras más utilizadas por Freud -y una de las fructíferas- para justificar sus inferencias causales, argumentando sobre la analogía y la falta de analogía entre el modelo ya conocido y lo que se pretende conocer.

Por otro lado, en una buena inferencia convergen distintos tipos de evidencia. Esto es lo que se llama consiliencia.

Por último, la mejor explicación es aquella que cumple otros dos criterios. A saber, hacer probable un evento o fenómeno que es improbable y tiene la consecuencia de explicar hechos desconocidos al momento de inferirla. Según el autor, el psicoanálisis es capaz de cumplir, también, con estos dos criterios, incluso utilizando los datos clínicos.

En conclusión, la obra de Edelson aporta una reflexión en el análisis metodológico y epistemológico que el psicoanálisis como disciplina científica se debe a sí misma, y como el propio autor nos advierte, estas problemáticas no deben circunscribirse al interés de filósofos de la ciencia e investigadores, sino también a los psicoanalistas en su práctica clínica diaria. 


\section{Referencias}

Edelson, M. (1988). Psychoanalysis: A theory in crisis. Chicago: Univ. of Chicago Pr. 